\title{
The Kaleckian model of growth and distribution and its neo-Ricardian and neo-Marxian critiques
}

\author{
Marc Lavoie*
}

This paper analyses the newer Kaleckian models of growth and distribution and the criticisms that have been addressed to them by neo-Marxian and neo-Ricardian authors. The models discussed assume overhead labour costs and target return pricing. The main issues are the form of the investment function and the notions of normal rates of profit and of normal rates of capacity utilisation. Despite the relevance of (and often the similarity between) the neo-Mancian and neo-Ricardian critiques, it is shown that the main features of the Kaleckian growth model may still be preserved.

(C) 1995 Academic Press Limited

\section{Introduction}

Post-Keynesian economics is still mostly known for the models of growth and distribution that were developed by Kaldor (1957), Robinson (1962) and Pasinetri (1962) in the late fifties and in the early sixties. For this reason, it is important to distinguish between those earlier models of growth and the newer models that have been recently proposed by post-Keynesian authors associated with the Kaleckian tradition. We shall call neo-Keynesian the older models, while we shall call Kalectian the newer ones.

There are two major related differences between the two groups of models that one should note. First, the neo-Keynesian models, because they are still being inspired by the framework developed by Keynes, are basically set in a world of competition, whereas the post-Keynesian models of Kaleckian inspiration are part of an oligopolistic framework. The second difference between the two models is that the older neo-Keynesian model implicitly presumes that in the long period the economy runs at full capacity or that the rate of utilisation of capacity is fixed at a given normal level, whereas in the newer post-Keynesian model the rate of utilisation of capacity is endogenous and is not assumed to be equal to a normal value, even in the long period (Kurz, 1993, 1994).

\footnotetext{
Manuscript received 18 September 1992; final version received 20 September 1993.

-University of Otzawa, Canada. This paper was presented at Carleton University and at the meetings of the Eastern Economic Associntion in March 1992, and also at the LATAPSES research centre of the Univensity of Nice at Sophia-Antipolis in June 1992. Besides the participants at those presentations, I would like to thank Richard Arena, Triah Cahill, Mario Seccareccia and Peter Skott for their comments at various stages of the paper. An anonymous reader of the journal also provided helpful and perceptive comments, which led to substantial revisions of the paper. This article was made possible by a grant from the Sacial Sciences and Humanivies Research Council of Canada.
} 
There are important consequences to the adoption of those differing assumptions, despite the other similarities of the two models. Perhaps the most crucial one is that in the neo-Keynesian one-sector model there is a necessary long-period inverse relationship between the real wage rate and the rates of profit and of accumulation. ${ }^{1}$ As Amadeo (1986B) recalls, neo-Keynesian models share this antagonistic description of accumulation with neo-Marxian models, and it is in conformity with the old classical notion that in the long period a unique and inverse relation between the real wage rate and the rate of profit must obtain. By contrast, in the Kaleckian model, there is usually a positive long-period relationship between the real wage rate and the rates of profit and of accumulation. ${ }^{2}$ This implication of the Kaleckian model of growth conforms with standard post-Keynesian short-period results, where increased real wages induce higher rates of capacity utilisation. ${ }^{3}$

It seems that the Kaleckian model of growth and distribution was originally developed independently by Bob Rowthorn and Amitava Dutt (Amadeo, 1987, p. 75), but the main results of their model were also arrived at by Del Monte (1975) in a paper published in Italian. Several other works have been published using a very similar framework. The exact growth model to be presented here is closest to the one displayed by Rowthorn (1981).

There are four crucial aspects according to which the ensuing model may be unambiguously called a Kaleckian model of growth and distribution. First, there is the investment function, about which more will be said later. Second, prices relative to direct costs are influenced by a broad range of factors, often summarised under the phrase 'degree of monopoly', and are thought to be little influenced by the level of demand. Prices are of the cost-plus type, within the context of oligopolistic market structures. Third, marginal costs are assumed to be constant up to full capacity, and overhead labour costs are taken into account. Fourth, in contrast to earlier Kaldorian hypotheses, the rate of utilisation of capacity is assumed to be generally below unity, and labour is assumed not to be a constraint. ${ }^{4}$

The long-period results at which Kaleckians arrive, notably the positive relation between the real wage rate and the rate of accumulation, have been questioned by various neo-Ricardian and neo-Marxian authors. The aim of the present article is to present these various criticisms within the framework of the Kaleckian model, and to show that there are substantial similarities between the formal neo-Marxian critique and the less formal neo-Ricardian objections to the Kaleckian model. It should be pointed out that such

\footnotetext{
' In a two-sector model the negative relation between real wages and the rate of accumulation need occur only under the classical hypothesis of no savings out of wages (Spaventa 1970, p. 140).

${ }^{2}$ Again, in a one-sector model, the positive relation between real wages and accumulation need occur only under the classical hypothesis of no savings out of wages (Nichols and Norton, 1991; Lavore, 1992, p. 345). This is an additional objection to the cooperative capitalism view implicit to the Kaleckan model (Sarkar 1993).

${ }^{3}$ For instance, Nell (1985, p. 176) writes: 'Is it, in fact, the case that a nse in the growth rate at full capacity can only come about through a fall in real wages? This is certainly the neo-Keynesian tradition, and it is also in the spirit of Ricardo and Marx, but is it really true? The serious question is whether this is a good way to theorise about increasing the growrh rate when the economy is operating at what is regarded as the normal level of capacity utilisation, let alone during a period of stagnation'.

-This is an obvious Kaleckian fearure, as the following quotation demonstrates: 'A considerable proportion of capital equipment lies idle in the slump. Even on average the degree of utlization throughout the business cycle will be substantially below the maximum reached during the boom. Flucruations in the utijsation of labour parallel those in the utilisation of equipment. The reserve of capital equipment and the reserve army of the unemployed are typical features of capitalsst economy at least throughout a considerable part of the cycle' (Kalecki, 1971, p. 137).
} 
comparisons are possible because it now has been recognised by economists of various schools that excess capacity may play a role both in the short and in the long period. We shall see that most of the objections to the Kaleckian model can be regrouped around discussions of the investment function on the one hand, and around the meaning of normal rates of profit and normal rates of capacity utilisation on the other hand. Possible answers to the objections will also be discussed.

The paper focuses on the simple Kaleckian model, set without reference to the financial sector nor to the external sector. ${ }^{1}$ The possibility of introducing a rate of interest distinct from the rate of profit, although work has been done to this effect, will be disregarded. ${ }^{2}$ Problems associated with a multi-sector framework are also ignored and as a consequence neither the question of a uniform rate of profit, ${ }^{3}$ nor the issues brought up by Steedman (1992) with respect to the validity of the mark-up approach, will be discussed directly. In particular, the capital-capacity ratio will be taken as constant, and it will be assumed that changes in real wages have no impact on the choice of technique.4 It will be further assumed that the short-period supply of output can be immediately adjusted to demand, as is usually supposed in Keynesian models. ${ }^{5}$ We start by presenting the essentials of the Kaleckian model of growth and distribution.

\section{The canonical Kaleckian model}

The profits cost equation

There are three crucial equations in the Kaleckian model. We start out with the derivation of what Rowthorn $(1981$, p. 8) and Steindl $(1979$, p. 3) call the profits function, which we shall call the profits cost equation. From national accounting, we have that the value of output is equal to the sum of the wage costs and the profits on capital:

$$
p q=w L+p p K
$$

where $p$ is the price level, $q$ is the level of real output, $w$ is the normal wage rate, $L$ is the level of labour employment, $r$ is the rate of profit, $K$ is the stock of capital in real terms. This may be rewritten as:

$$
p=w(L / q)+r p K / q
$$

In most Kaleckian models, only variable labour is taken into consideration. Here, in the Kaleckian tradition of Asimakopulos (1975) and Steindl (1979, p. 3), we follow Rowthorn (1981) and Kurz (1991) by taking into account fixed or overhead labour $\left(L_{f}\right)$ as well as variable labour $\left(L_{v}\right) \cdot{ }^{6}$ We then make use of the following definitions:

The amount of labour employed:

$$
L=L_{v}+L_{f}
$$

\footnotetext{
${ }^{1}$ See Taylor (1991) and Sarantis (1990-91).

${ }^{2}$ See Skott (1989), Taylor (1991), Dutt (1992) and Lavoie (1995).

${ }^{3}$ For discussions about gravitation and the convergence towards classical prices of production, a reader is referred to the special issue of Political Economy (1990). The likelihood of convergence in the specific case of multi-sector models of cost-plus prices is discussed in more detail in Boggio (1992).

- See Kurz $(1986,1990)$ for studies on the meaning of normal rates of utilisation in the context of the choice of technique. See Kurz (1991) and You (1994) for studies of technical progress.

"In the terms of Dumenil and Levy (1987, p. 140), the model is one of equilibrium dynamics.

- The importance of overhead labour for growth models has been lately underlined by Nichols and Norton (1991).
} 
The rate of utilisation of capacity, with $q_{f c}$ full capacity output:

$$
u=q / q_{f c}
$$

The capital to capacity ratio:

$$
v=K / q_{f c}
$$

The average or marginal productivity of variable labour:

$$
y_{v}=q / L_{v}
$$

The requirements in fixed labour, assumed to depend on output capacity rather than actual output:

$$
y_{f}=q_{f c} / L_{f}
$$

The ratio of fixed labour to variable labour, the latter being defined at full capacity output, is assumed to be fixed. Calling $f$ such a ratio, it follows from its definition and from equations (6) and (7) that $f$ is equal to:

$$
f=y_{v} / y_{f}
$$

With these definitions, equation (2) can be rewritten as:

$$
p=w\left(1+f(u) / y_{v}+r p v / u\right.
$$

Equation (9) gives us the price of a unit of output in terms of the labour costs per unit of output and the profits per unit of output. ${ }^{2}$ Note that the first element of the right-hand side of equation (9) is simply average cost per unit at the actual rate of utilisation of capacity. From this equation, we obtain the profits cost equation in terms of the real wage rate:

$$
r=(u / v)\left\{1-(w / p)(1+f / u) / y_{v}\right]
$$

Kaleckian models are often expressed in terms of the gross profit margin $m$. To do so, we have to introduce a pricing equation. Post-Keymesians usually rely on some cost-plus pricing procedure. We shall consider two of these. The first one is the simple mark-up procedure on unit direct costs. Here, as we deal with a single verticallyintegrated sector, all direct costs come down to labour costs, so the mark-up pricing procedure becomes:

$$
p=(1+\theta) w / y_{v}
$$

The gross margin of profit $m$, or Kalecki's degree of monopoly, is a simple function of the mark-up $\theta$. It is given by:

$$
m=\theta /(1+\theta)
$$

From the above three equations, we obtain the profits cost equation of the Kaleckian growth model:

$$
r=u(m / v)-(1-m) f / v
$$

The rate of profit is a function of the rate of utilisation of capacity and of various parameters, including the gross profit margin.

\footnotetext{
1 One could introduce a parameter, say $\sigma=w / w$, which would signal the ratio between the average salary pard to overhead labour, $w_{\rho}$ and the average wage paid to variable labour, wi. With such an addition, there would be no change to the equations, except that the product of would replace the parameter $f$ wherever it appears (cf. Nichols and Norton (1991), and Lavoie (1992, ch. 6)).
} 
Target retum pricing

While Kaleckians themselves seem to have favoured mark-up pricing, one is not forced to adopt this type of cost-plus pricing procedure. Indeed, it has been argued by Lee (1985) that pricing procedures are to a large extent dependent on accounting procedures, and that the latter have long been sophisticated enough to support normal cost pricing procedures, also called by some full cost pricing. Such pricing is based on unit costs, or rather standard unit costs, rather than unit direct costs only. A particular specification of normal cost pricing is target return pricing, and it seems to be prevalent today (Lanzillotti, 1958; Shipley, 1981). A well-known example of target return pricing is General Motors.

GM begins its pricing analysis with an objective of earnings, on the average over the years, a retum of approximately 15 per cent after taxes on total invested capital. Since it does not know how many autos will be sold in a forthcoming year, and hence what the average cost per unir (including prorated overhead) will be, it calculates costs on the assumption of standard valume-that is, operation at 80 percent of conservatively rated capacity. A standard price is next calculated by adding to average cost per unit at standard volume a sufficient profit margin to yield the desired 15 per cent after-tax return on capital. (Scherer, 1970, p. 174)

Some Kaleckians seem to agree to this sort of pricing procedure, without necessarily using it explicitly. For instance, Asimakopulos (1975, p. 319) argues that 'mark-ups are designed to cover, over time, both overhead costs and profits. Their values would thus be dependent on the standard rates of utilisation of productive capacity used to calculate standard costs as well as on some expected rate of return'. ${ }^{1}$ We can find an explicit pricing formula for target return procedures that is almost as simple as the mark-up equation (11). To do so, we define the standard rate of utilisation of capacity, $u_{s}$. First note, with the help of equation (9), that unit costs at standard volume are equal to: $w\left(1+f / u_{s}\right) / y_{v}$. Target return pricing would then be such that:

$$
p=\left(1+\theta^{\prime}\right) w\left(1+f / u_{s}\right) / y_{v}
$$

What then would $\theta^{\prime}$ be equal to? Suppose that the replacement value of the stock of capital is $p K$, while the target rate of return, to which we shall also refer as the standard rate of profit, is $r_{s}$. Required profits for the period are then $r_{s} p K$. With a standard rate of utilisation of capacity of $u_{s}$, corresponding in the period to a level of output of $q_{s}$, the required profits for the period must be equal to $r_{s} v p q_{s} / u_{s}$. This must be equated to the total profits that are to be obtained by marking up unit costs at the standard rate of utilisation of capacity: $q_{s} \theta^{\prime} w\left(1+f / u_{s}\right) / y_{v}$. After some manipulation, a simple pricing formula for target pricing procedures emerges:

$$
p=\left(\frac{u_{s}+f}{u_{s}-r_{s} v}\right) \frac{w}{y_{v}}
$$

Of course, the equation makes sense only if the denominator is positive, that is, if $u_{s}>r_{s} v$. The inequality must by necessity be fulfilled since it implies that wages are positive, i.e., profit income is smaller than total income. When this target return pricing formula is combined with equation (10), the profits cost function becomes:

$$
r=\left[\left(f+r_{s} v\right) u-\left(u_{s}-r_{s} v\right) f\right] / v\left(u_{s}+f\right)
$$

\footnotetext{
${ }^{1}$ Asimakopulos's model is very similar to the one presented here. It includes overhead labour costs, but is set in the short period only.
} 
One should note that if the actual rate of utilisation of capacity $u$ tums out to be equal to the standard rate of utilisation of capacity $u_{s}$, the actual rate of profit $r$ is then equal to the target rate of return $r_{s}$ embodied in the margin of profit of the pricing procedure. This can be seen more clearly by rewriting equation (16) under the form of equation (17).

$$
r=r_{s}\left(\frac{u+f}{u_{s}+f}\right)+\frac{\left(u-u_{2}\right) f}{v\left(u_{s}+f\right)}
$$

Since equation (16) is linear in $u$, it clearly shows that the standard and the actual rate of utilisation of capacity cannot be equal unless the standard and the actual rates of profit are equal. This result will be quite useful in Section 4 .

\section{Effective demand}

The previous equations define a rate of profit seen from the cost accounting side. Effective demand has not yet been taken into account. In the neo-Keynesian models, the rate of accumulation is taken to be exogenous, so that the Cambridge equation can be interpreted as fully representing the notion of effective demand. A crucial feature of the Kaleckian model is its investment function. The Cambridge equation must thus be reinterpreted as a savings function. With the standard assumptions, i.e., there are no savings out of wages and salaries or the Pasinetti (1962) conditions apply, the savings function in growth terms becomes:

$$
g^{s}=r_{p}
$$

with $s_{p}$ the overall propensity to save out of profits.

We now come to the investment function, which, as will be seen, has been the main subject of contention. Both Rowthorn (1981) and Dutt (1984; 1990) use Kaldor's (1957) investment function expressed in growth terms:

$$
g^{\prime}=\gamma+g_{2} u+g_{\gamma} r
$$

where $\gamma$ is some parameter, which must be positive in the models without overhead labour (Dutt, 1990, p. 25), but which can be negative in the models with overhead costs.

Note that investment decisions depend positively on both the rate of profit and the rate of utilisation. Putting together equations (18) and (19), one obtains what Rowthorn $(1981$, p. 12) calls the realisation curve. We shall call it the effective demand equation:

$$
r=\left(g_{u} u+\gamma\right) /\left(s_{p}-g_{r}\right)
$$

The steady-state solution to this Kaleckian model of growth and distribution can be obtained by combining the profits cost equation and the effective demand equation. In the case of the simple mark-up procedure, we use equations (13) and (20). A graphical solution is offered in Fig. 1. The model is stable provided:

$$
s_{p}>g_{r}+g_{u} v / m
$$

The model contains two crucial features. First, Keynes's paradox of thrift holds, even in the long period. A decrease of the propensity to save would shift up the effective demand curve, labelled ED in Fig. 1, and hence generate higher rates of profit, utilisation and accumulation. The paradox of thrift proves to be very resilient to critiques, although it will not be discussed any further. Second, there is the paradox of cost: any increase in costs raises the rate of profit (Rowthorn 1981, p. 18). This can be shown by taking the partial derivative of equation (13) with respect to $m$. This derivative is obviously positive. 


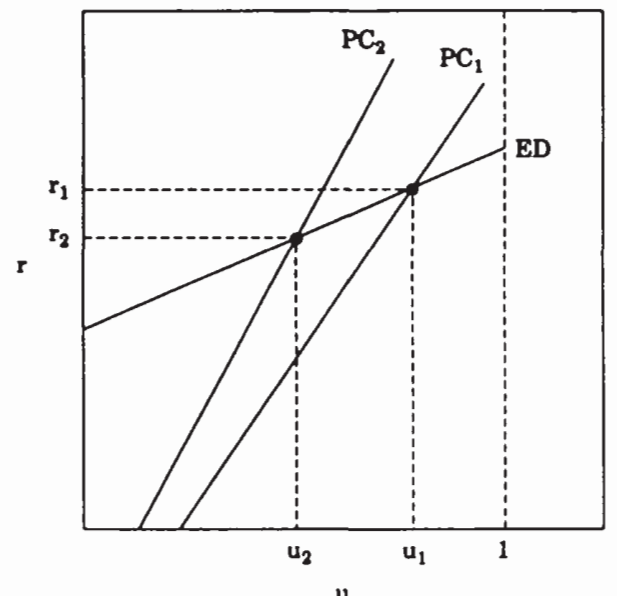

u

Fig. 1. The paradox of costs: lower real wages induce a lower rate of profit.

An increase in the mark-up or in the gross profit margin $m$ thus entails an upward shift of the profits cost curve, labelled PC in Fig. 1. A lower real wage rate is thus associated with a lower rate of utilisation, a lower rate of profit, and hence a lower rate of accumulation. ${ }^{1}$

Since these positive relations go against the classical beliefs that accumulation requires sacrifices and that labour and capital interests are necessarily dissonant, it will surprise no one that some neo-Ricardian and neo-Marxian authors have questioned those implications of the Kaleckian model, on various grounds. ${ }^{2}$

\section{The critique of the Kaleckian investment function}

On the similarity between the neo-Ricardian and the neo-Marxian critiques

Besides the rejection of mark-up prices as relevant long period prices, the main neo-Ricardian response to the positive relation between real wages and profit rates has been the denial of the relevance of a rate of utilisation that would be different from its standard rate. The neo-Ricardians call this standard rate the normal rate of capacity utilisation. Two approaches have been taken. One is to deny that the rate of utilisation in the long period may be any different from its normal rate. We shall deal with this position later. The second approach is to deny that the current rate of utilisation has any impact on investment decisions. ${ }^{3}$ This is the position that we now tackle.

${ }^{1}$ From his Kaleckian model of accumulation, Del Monie (1975, p. 243) concludes: 'Our model confirms what is usually observed in the real world, that is, an increase in the degree of monopoly diminishes the rate of utilisation of plants and the rate of growth. When firms decide to reduce the real wages of workers, the result is not an increase in the rate of profit, but rather a decrease in the rate of profit, because the higher degree of monopoly has led to fall in the rate of utilisation of capacity' [my translation].

${ }^{2}$ Ironically, but rightly so, Kurz (1993, p. 78) attributes to the neo-Keynesians the belief that 'the distributive conflict holds full sway over the long period', adding that such a position cannot be accepted.

${ }^{3}$ Some neo-Ricardians have adopted the first position, only to later switch to the other. Vianello (1989, p. 188) writes that 'it was only after reading Dr Ciccone's aricle that I realised that I had no need to bring in the tendency of productive capacity to adjust when arguing away the alleged influence of current on expected capacity'. 


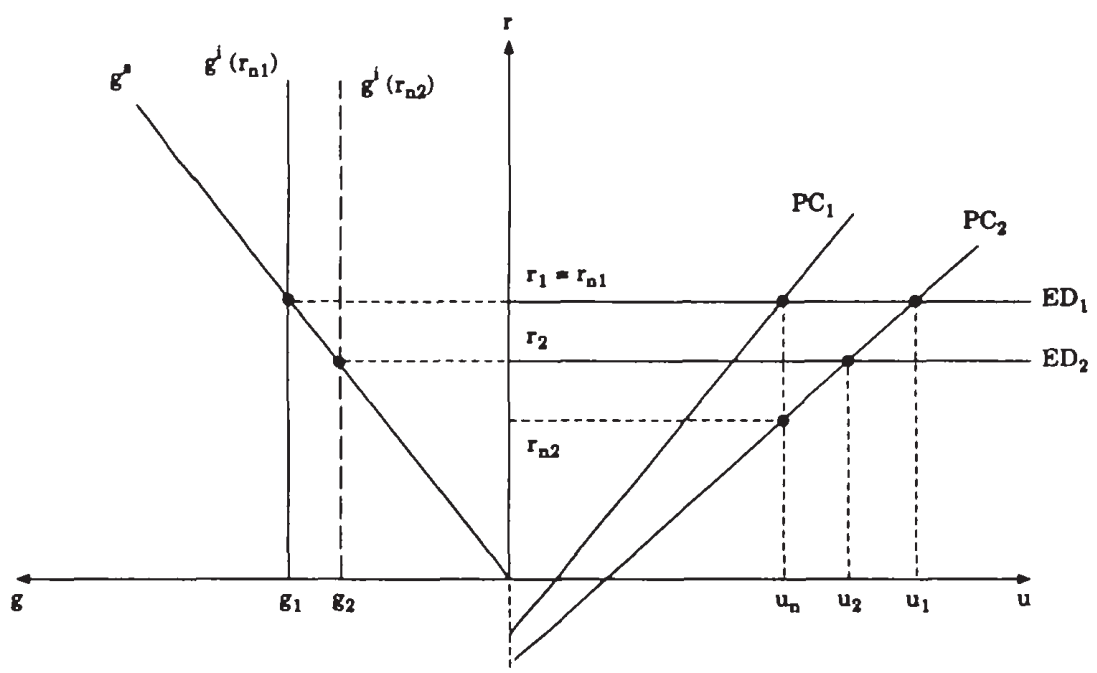

Fig. 2. The classical view: a lower normal rate of profit induces lower accumulation.

While some neo-Ricardians recognise that the rate of utilisation in the long period may be different from its normal rate, they dispute that current profitability could have any influence on expected profitability. This objection is related to the investment function. The view of both Ciccone (1986, p. 26) and Vianello (1989), and also of Garegnani (1992, p. 56) and Kurz (1992, p. 22), is that new investment depends on expected profitability, computed at normal prices based on the normal rate of utilisation of capacity. This means that the investment function depends on the (expected) normal rate of profit rather than on the actual rate of profit. The justification for this is that entrepreneurs cannot make future plans under the assumption that capacity will be perpetually over-utilised. Plans must be made according to profitability at normal use of capacity. The rate of profit that represents 'the guiding light for investment and pricing decisions, cannot possibly be either an abnormally high or an abnormally low one' (Vianello, 1985, p. 84). Assuming as an extreme case that the actual rate of utilisation has no impact on the investment function, the neo-Ricardian investment function could be written as follows, with $r_{n}$ denoting the (expected) normal rate of profit:

$$
g^{j}=\gamma+g_{r} r_{n}
$$

Vianello's (1989) main argument is that Kaleckian authors fail to understand that expected profitability is hindered by a rise of real wages, even if actual profitability stays constant in the short and medium run. This fall in the expected normal rate of profit eventually leads to a fall in investment activity, and hence to a fall in the actual rate of profit, thus justifying to some extent the pessimistic expectations. This reasoning is illustrated in Fig. 2. Suppose we start from a fluke situation in which the savings and the investment functions, $\mathrm{g}^{3}$ and $\mathrm{g}^{\prime}\left(r_{n 1}\right)$, are such that the rate of utilisation and the actual rate of profit happen to be at their normal rates, $u_{n}$ and $r_{n 1}$. The initial profits cost curve is given by $\mathrm{PC}_{1}$ and the effective demand curve must be $\mathrm{ED}_{1}$. Now let us assume an increase in the real wage, with no change in the technical coefficients. This implies a 
downshift of the profits cost curve to $\mathrm{PC}_{2}$. In the short period, with no change in the rate of accumulation, and hence no change in the actual rate of profit, the actual rate of utilisation of capacity rises to $u_{1}$. It is this rise in the rate of utilisation that allows actual profitability to stay constant, despite the rise in wage costs.

According to Vianello, however, this situation will not last. Entrepreneurs will revise their view of the normal profit rate, taking into account the new real wage rate. The new normal profit rate $r_{n 2}$ is given by the intersection of the new profits cost curve $\mathrm{PC}_{2}$ and the normal rate of utilisation $u_{n}$. The desired rate of accumulation-given by equation (22)-falls to $\mathrm{g}^{\mathrm{i}}\left(r_{n 2}\right)$, thus inducing a downshift of the effective demand curve to $\mathrm{ED}_{2}$. At the end of the process, the normal and the actual rates of utilisation will usually diverge, as will the actual and normal rates of profit. The new actual rate of profit, that is $r_{2}$, is below the initial rate of profit $r_{n 1}$, despite real wages having increased and despite the rate of capacity utilisation being endogenous. Although the rate of utilisation does not necessarily equal the normal rate of utilisation nor unity, the negative relation between the real wage rate and the rate of profit is recovered, as the neo-Ricardians would have it. Similarly, the long-period negative relation between the real wage rate and the rate of accumulation is restored. ${ }^{1}$

One need not, however, make the extreme assumption that the actual rate of utilisation of capacity has no induced effect on the investment function. One may presume that firms take normal profitability into account while still responding to the actual rate of capacity utilisation. ${ }^{2}$ Noting that normal profitability is related to the normal rate of capacity utilisation in accordance with equation (13), that is, the profits cost equation, the 'neo-Ricardian' investment function of equation (22) would then become:

$$
g^{2}=\gamma+g_{\mu^{\prime}} u+g_{\nu} r_{n}
$$

This is precisely what Bhaduri and Marglin (1990) offer as an investment function. They contend, as do Kurz (1991) and other neo-Marxians such as Epstein (1994), that the investment function, if linear, should be of the following form:

$$
g^{j}=\gamma+g_{u} u+g_{m} m
$$

Here, as before, $m$ represents the gross margin of profit, derived from the mark-up on variable costs, and $g_{m}$ represents the sensitivity of investment to changes in the margin of profit. Bhaduri and Marglin seem to argue that investment activity depends on a single variable, the actual rate of profit. That rate can, however, be decomposed into the rate of utilisation of capacity and the net share of profits $\pi$ in national income, that is:

$$
r=\pi u / v
$$

\footnotetext{
' 1 believe Fig. 2 is a correct graphical representation of Ciccone's and Garegnani's literary models. Once the new normal profit rate has been inserted within the new investment function, the relation between the $\mathrm{ED}_{2}$ and $\mathrm{PC}_{2}$ curves could be such that the actual (average) profit rate $r_{2}$ is smaller or larger than (or even equal to) the normal profit rate $r_{n 2}$. According to Ciccone, while prices gravitate around their normal values, the actual rates of capacity utilisation need not. Here I understand Ciccone $(1986,1987)$ and Garegnan (1992) as saying that while prices and invesument decisions incorporate the normal profit rate $r_{n 2}$, the actual rate of utilisation $u_{2}$ may on average be greater or smaller than $u_{n}$.

${ }^{2}$ For instance, Garegnani (1992, p. 62) writes that 'the normal rate of profits will be that on which [the entrepreneurs] will base their decision to invest - a rate which, as we saw, will need bear no close relation to a ratio between aggregate actual net profits and aggregate existing capital'. But he also recognises that 'a high past level of utilization of the plant might well result in a higher amount of investment, and a larger new plant ...' (1992, p. 56).
} 
In the special case where there is no overhead labour, the net share of profits $\pi$ and the gross margin of profit $m$ are identical. Strictly speaking, when there are overhead costs, an investment function based on the definition of the actual rate of profit should depend on the net share of profits $\pi$ rather than the gross margin of profit $m$. We shall return to this distinction, which is only relevant, at least in one-sector models, in the case incorporating overhead costs.

Broadly speaking then, the argument of Bhaduri and Marglin is based on equation (25). They say that an increase in the actual rate of profit may be due either to a rise in the actual rate of capacity utilisation or to a rise in the margin of profit. When investing, firms would separate the effects on profits due to effective demand from those which follow from the firm's ability to cut its costs relative to prices. Bhaduri and Marglin (1990, p. 391) demonstrate that the canonical Kaleckian investment function, equation (19), when compared to equation (24), imposes restrictions on the relative response of investment to the two constituents of the profit rate. In their own equation, the rate of utilisation plays no role in addition to that played as part of the actual rate of profit.

While the arguments advanced by neo-Marxians and neo-Ricardians may appear different, they are in the end identical. This can most easily be seen by getting rid of overhead costs in the profits cost equation (13), and finding the normal rate of profit corresponding to a normal use of capacity: One gets:

$$
r_{n}=m u_{n} / v
$$

As long as normal capacity utilisation $u_{n}$ and the capital to capacity ratio $v$ are constants, any change in the gross margin of profit $m$ implies a change in the normal rate of profit $r_{n}$. Clearly, then, the investment function proposed by Marglin and Bhaduri as a replacement for the Kaleckian investment function is a variant of Vianello's case against the use of current profitability as an argument of the investment function. Bhaduri and Marglin (1990, p. 388), as well as Vianello (1989, p. 183), argue that Kaleckians have omitted the depressing cost effects of higher wages on economic activity. Equation (26) makes clear that the proponents of equation (24) suppose that, if the rate of profit is to be taken into consideration in addition to the rate of capacity utilisation, it should be calculated at the normal rate of utilisation. Those who are saying that the margin of profit $m$, rather than the actual rate of profit $r$, should enter the investment function in addition to the rate of utilisation of capacity are making an argument which is no different from the assertion that the normal rate of profit $r_{n}$, rather than the actual one, should be included in the investment function in addition to the rate of utilisation of capacity. The neo-Ricardian and the neo-Marxian objections to the Kaleckian investment function are thus in the end identical.

\section{Kaleckian responses to the critiques}

That the Kaleckian investment function implies unwarranted restrictions seems to be a fairly valid point, which cannot be disputed on logical grounds. Indeed, this point may even be attributed to the Kaleckians themselves, since it is Steindl who argued that one needs to distinguish "between those shifts to or from profits which are due to effective demand, and those which result from changed price-cost relations independent of demand' $\left(1979\right.$, p. 3). ${ }^{1}$ The use of equation (24) combined to the rest of the Kaleckian model allows Bhaduri and Marglin (1990), as well as others such as Kurz (1991) and

\footnotetext{
'Steandl made the same point earlier: 'The net profit margin can, in fact, change for two quite different reasons: either because of a change in utilisation of capacity, with an ocherwise unchanged structure of costs and prices; or the net profit margin can change at a given level of utitisation of capaciry' (1952, p. 46).
} 
Taylor (1991, ch. 3), to demonstrate that several regimes are possible, and that there may or may not be a positive relationship between the real wage rate and the rate of accumulation. It must be noted, however, that Bhaduri and Marglin (1990, p. 385) do not put much weight on this investment function to justify the possibility of a profit squeeze regime. They consider their results more compelling when associated with an open economy. The income elasticity of imports could eventually lead to a deterioration of the trade balance, annihilating the expansionary effects of higher real wages (cf. Blecker, 1989). Staying within the confines of a closed economy, however, several reasons can be advanced in favour of the Kaleckian investment function over the Marxian/neo-Ricardian investment formulation.

One may hesitate to incorporate the margin of profit (or the normal rate of profit) as one of the determinants of the investment function in a macroeconomic model for at least five different reasons. Most of these reasons have to do with factors entrepreneurs face when operating in an economy set in actual time. First, it is not clear that an increase in the margin of profit that corporations try to impose at the normal degree of capacity utilisation necessarily implies better profitability. This follows an argument put forward by some neo-Ricardians. According to Pivetti (1988, p. 282), 'the interest rate determines the markup of prices over nominal wages'. An increase in the margin of profit may thus be the result of an increase in the perceived permanent rate of interest. ${ }^{1}$ This does not necessarily entail good news for the entrepreneurs in contrast to the rentiers. Second, as has been argued by Dutt (1990, p. 223), firms may be looking at the overall economy, rather than at their own situation, to judge the expected profitability of their investment plans. If this is so, firms would not be able to assess the current normal rate of profit as the neo-Ricardians explicitly argue. The available information would only allow entrepreneurs to estimate the actual rate of profit. As a consequence, the rate of profit rather than the margin of profit or the normal rate of profit again would have to be the variable entering the investment function. Third, the choice of the proper variable in the investment function may depend on the time horizon involved. If the lifetime of the investment project is shorter than the number of years expected to be needed for the actual rate of utilisation to come back to its normal rate, it would be more reasonable for firms to base their decisions on actual rates rather than normal rates. This last argument, and the one to follow, would probably convince economists concerned with sequences of short runs, such as the Kaleckians, whereas they would have less impact on those economists more preoccupied with the atemporal long-period analysis, such as the neo-Ricardians. ${ }^{2}$

A fourth reason, based on the dynamics of effective demand in actual time, could also be offered in favour of the Kaleckian investment function. Going back to the example given in Fig. 2, it can be shown that in the transition period during which the rate of capacity utilisation increases from $u_{n}$ to $u_{b}$ the growth rate of sales is higher than that prevailing in the initial steady-state. We know from equations (4) and (5) that $q / K=u / v$, and hence in growth terms that:

$$
\hat{q}=g+\hat{u}-\hat{v}
$$

'The margin of profit would then be written as:

$$
m=m_{0}+m_{i} i
$$

where $m_{1}$ is a positive parameter and $i$ is the nominal or real rate of interest. See Dutr (1992B) and Lavoie (1992, ch. 6).

${ }^{2} \mathrm{See}$, among others, Halevi and Kriesler (1991). For a distinction between long-period positions as a notional state and long run as a duration of time, sce Caravalho (1992, p. 19-25). 
Even though the rates of profit and of accumulation are assumed constant from one steady-state to another, an increase in real wages will induce both a higher rate of capacity utilisation and a transitional increase in the growth rate of sales $(\tilde{q})$. The result is intuitive: the rate of utilisation rises because sales are rising faster than the installation of new capacity. This should have a positive impact on the expectations and animal spirits of entrepreneurs in a world of uncertainty, independently of its impact on the rate of profit, and regardless of the fall in the gross margin of profit or in the rate of normal profit.

The final and crucial justification of the standard Kaleckian investment function, however, is the finance frontier (Agliardi, 1988, p. 284). Unless investment expenditures are entirely financed by retained earnings, firms can only invest as long as they can convince banks that they are worthy borrowers. Retained earnings are thus an important element of the investment function, independently of any effect that a high rate of capacity utrlisation may have on the desire to invest. The normal rate of profit, or the margin of profit, may be a good indicator of profitability of investment to be expected for the future; but the realised rate of profit is also a good indicator of the borrowing possibilities of firms. ${ }^{1}$

The independent influence of the rate of utilisation over investment has been verified empirically by many authors, notably by Fazzari and Mott (1986-87): in a time-series study, they show that the sales and retained earnings of firms each have a positive impact on investment expenditures, while their flow of interest payments has a negative influence on investment. Similarly, Chamberlain and Gordon (1989) show that capacity utilisation and profitability net of interest payments are significant determinants of investment. Those findings are entirely compatible with the investment function proposed by Kaleckians in general and Steindl in particular. They highlight the importance of the rate of utilisation, independently of its effect on the realised rate of profit.

\section{Profit shares with overhead labour}

A major reason for which the investment function and the results of the standard Kaleckian model have been questioned is that some authors do not believe that the canonical Kaleckian model and its main stagnationist view correspond to the stylised facts of the last two decades. In the Kaleckian models without overhead costs, a rise in real wages is necessarily associated with a rise in the share of wages and with a rise in the rate of accumulation. Neo-Marxian authors, however, note that in the recent past rising wage shares have been associated with lower rates of accumulation. ${ }^{2}$ A sample of this view is presented below:

Recent trends in income distribution and economic growth in the OECD countries seem, at least at first sight, to cast doubt upon the stagnationist view. A number of studies have found that wage shares rose and profit shares fell in the United States and other western countries sometime after the mid-to-late 1960s. This distributional shift roughly coincides with the period of 'stagflation', or slower growth, accompanied by inflationary pressures. (Blecker, 1989, p. 395)

1 This factor was underined not only by Kalecki (1971, p. 111) but also by Robinson $(1962$, p. 86). In addition, the importance of realised profits, in contrast to normal profits, on the availability of finance for firms desiring to invest has been recognised more recently by neo-Ricardian authors: see Garegnani (1992, p. 62) and Roncaglia (1990, p. 110).

${ }^{2}$ See also Auerbach and Skott (1988) and Sarkar (1993). It must be said in defence of Blecker that Nell makes a very similar argument to support the Kaleckian model. Nell argues that the neo-Keynesian and Marxian inverse relation between real wages and growth cannot be valid, because since the 1940 s 'the share of wages and the rate of growth both increased' (1985, p. 176). 
It must now be noted that the model that has been developed above is impervious to that critique. There is no inconsistency between low shares of profit and low growth rates or low rates of utilisation in a Kaleckian model incorporating overhead costs, as we now show. Recall the definition of the rate of profit given by equation (25). The share of profits (net of fixed wage costs) is thus $\pi=r v / u$. Using this algebraic definition of the share of profits, we can substitute into it the effective demand function and the profits cost function, given by equations (20) and (13), to obtain the profit share as seen from the demand and supply sides respectively.

$$
\begin{gathered}
\pi^{d}=\left[v g_{u}+v \gamma / u\right] /\left(s_{p}-g_{r}\right) \\
\pi^{s}=m-(1-m) f / u
\end{gathered}
$$

It can be seen immediately that a rise in the degree of monopoly $m$ leads to a shift of the $\pi^{s}$ curve only, the shift being an upward one. As to the impact on the equilibrum share of profits, two cases arise depending on the sign taken by $\gamma$ (Rowthom, 1981, p. 21). When this parameter is positive, the $\pi^{d}$ curve is downward sloping, as illustrated in Fig. 3(a). A fall in real wages, that is an increase in the degree of monopoly, leads to an increase in the share of net profits from $\pi_{1}{ }^{\star}$ to $\pi_{2}{ }^{\star}$. Under these conditions, it would thus appear that the movements of the share of profits are countercyclical. The share of profits increases when the rate of utilisation, the rate of profit and the rate of accumulation all decrease as a result of the lower real wages. A specific instance of this case is the Dutt/Amadeo model without overhead costs, in which the $\gamma$ term cannot be negative, and where the $\pi^{3}$ curve is horizontal.

In the Kaleckian model with overhead costs, however, the $\gamma$ term can be negative. Such a situation occurs if positive profits are required for firms to invest. The $\pi^{d}$ curve is then positive, as is shown in Fig. 3(b). ${ }^{1}$ As in the previous case, an increase in the gross margin of profit $m$ shifts up the $\pi^{3}$ curve. This time, however, the share of profits falls from $\pi_{1}{ }^{*}$ to $\pi_{2}{ }^{\star}$. The movements of the share of profits are thus procyclical. The share of profits decreases, as does the rate of capacity utilisation, despite the increase in the gross margin of profit. In this case, which is just as likely as the other, the share of profits and the rate of accumulation increase together, just as they did in the earlier post-Keynesian models of Robinson and Kaldor. Readers may also verify for themselves, in both parts of Fig. 3, that a variation in the demand parameters that induces an upward shift of the $\pi^{d}$ curve results into an increase of both the rate of urilisation and the share of profits. This implies that for a given margin of profit the rate of accumulation and the share of profits increase together.

The stylised facts that have been observed in OECD countries are thus consistent with the stagnationist model: high mark-ups and low real wages may induce both slow growth and low net profit shares. High mark-ups are not synonymous with high profit shares in Kaleckian models with overhead costs. As Weisskopf (1979, p. 354) warns: 'Because of the overhead labour phenomenon, a rise in the share of total wages (hourly wages plus salaries), and hence a decline in the share of profits may result from a decline in the rate

\footnotetext{
'Note that the $\pi^{d}$ curve necessarily has a smaller slope than the $\pi$ ' curve. This requirement arises out of the necessity for the steady-state rate of capacity utilisation to be posiuve and because of the stability condition. Heunstically, it also can be seen that the $\pi^{d}$ curve cannot cut the $\pi^{*}$ curve from below, by noting that an increase of the mark-up would lead to an increase in the rate of utilisation, an impossible result within the strict Kaleckian model presented here.
} 
(a)

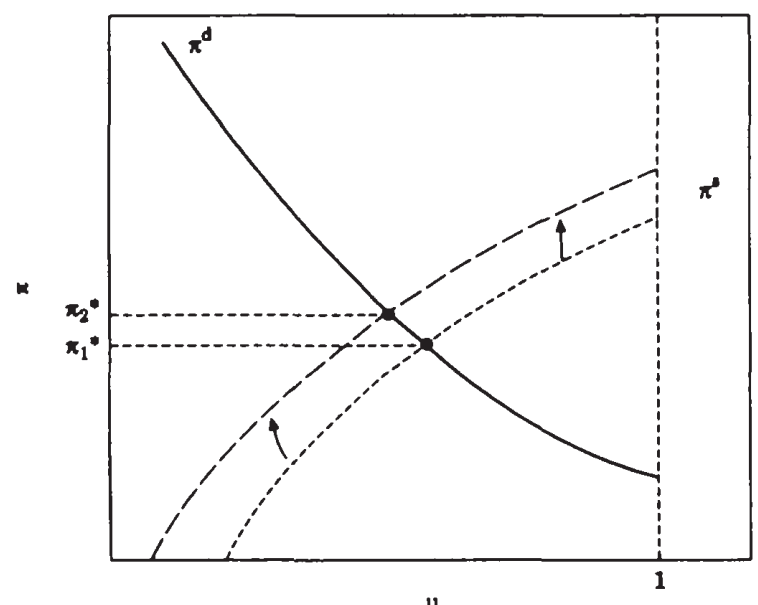

u

(b)

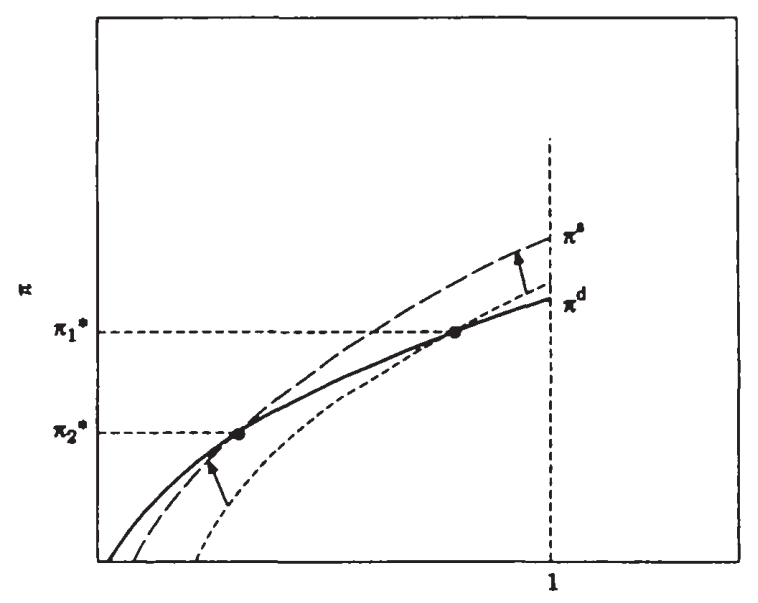

u

Fig. 3. (a) Lower real wages, and countercyclical mourments of the share of profits; (b) Lower real wages, and procyclical movements of the share of profis.

of capacity utilisation as well as a rise in the strength of labour'. The analysis of Fig. 3(b) also shows that one need not go beyond the confines of a one-sector model to prove that a higher real wage rate may be associated with a lower wage share, as Steedman (1992, p. 148) cautions us, provided the effects of effective demand and variable rates of capacity utilisation are taken into account. 


\section{Implications of various definitions of the normal rate of capacity utilisation on the Kaleckian investment function}

In previous discussion it was assumed that the actual rate of capacity utilisation can be different from the normal rate of utilisation in the long period. There are, however, several authors who believe that such a characterisation lacks consistency, or who contend that such a steady-state contains the seeds of its own destruction. We shall discuss in turn the implications of such criticisms for the investment function and the pricing equation. All the objections centre around the definition and meaning of a normal or standard rate of capacity utilisation.

In the course of the discussion, the concept of a fully adjusted position will be considered. Such a position will be defined as a situation which results from an adjustment process that occurs across long-period positions. The object of the adjustment process is to provide a convergence between the normal targets of the firm and their realised values. While the term 'fully adjusted position' is borrowed from Vianello (1985), it will be shown, in contrast to Vianello's use of the term, that even in fully adjusted positions the rate of capacity utilisation may still be considered endogenous.

Most of the discussion in Sections 3 and 4 will focus on whether the possible adjustment processes are stable or not. It should be pointed out that all conclusions are only valid for the linear model presented here; they would have to be reconsidered in a non-linear system where, for instance, there may be limit cycles such that instability would abound near the centre of gravitation of the long-period equilibrium, but where the stability would prevail away from this centre of gravitation.'

The normal rate of utilisation as cost minimisation

It has been argued by Kurz (1986) that the normal rate of utilisation of capacity could not be something defined by conventions. 'The normal rates of utilisation of the various items of plant and equipment are conceived to be in compliance with the principle of cost minimisation' (Kurz, 1986, p. 43). The normal rate of capacity utilisation is defined in this view according to the optimal choice of technique. This, however, cannot be considered a valid objection to the approach taken here. As Caserta (1990) points out, excess capacity has three dimensions. Utilisation can be increased by a more speedy operation of a plant, by longer or more numerous shifts of operation, or by putting to work machines that were previously idle. Only this last sort of excess capacity should be taken into consideration in models of the Kaleckian type (Caserta 1990, p. 151). ${ }^{2}$ Cost minimisation deals with the other two meanings of excess capacity.

One can thus assume that each plant or segment of plant is being operated at its most efficient rate, in compliance with the proper principles of cost minimisation. The full capacity of a firm is then the sum of all of its capacities so defined (Eichner 1976, p. 62). When the rate of utilisation of capacity is below unity, some of the segments or some of the plants are not being utilised at all. It does not mean that plants are being run unefficiently with inappropriate shifts. As Dutt (1990, p. 230) points out, while firms may control the pace at which each plant is being used, they have no control over the overall degree of capacity utilisation at the macroeconomic level. Cost minimisation and excess capacities are not incompatible: cost minimisation deals solely with the pace at which a

\footnotetext{
'See, for instance, Skott (1989) and Dutt (1992A).

${ }^{2}$ Many economists object to this third notion of excess capacity, and hence to Kaleckian models in general, by arguing that firms use fluctuations in inventories to adapt to the fluctuations in demand (cf. Kurz, 1986, p. 53).
} 
plant normally should be operated. This is generally unrelated to demand factors that set the actual rate of capacity urilisation and to the strategic and conventional considerations that determine the normal rate of capacity utilisation.

The normal rate of utilisation as a target

The rate of utilisation being clearly defined over the set of all plants, rather than at the level of the plant segment, we may now deal with the main objection to the Kaleckian long-period approach. This objection to the long-period inequality between the actual rate of capacity utilisation and the normal one is based on the presumption that the normal rate is a target of the firms. This is a criticism of Kaleckian models that can be found in Auerbach and Skott $(1988)$ and in Committeri $(1986 ; 1987)$. In their view, the normal rate of capacity is an optimal rate of utilisation that firms try to achieve, at least over the long run. Therefore, entrepreneurs would not be content unless the targeted rate of capacity utilisation is realised: 'It is inconceivable that utilization rates should remain significantly below the desired level for any prolonged period' (Auerbach and Skott, 1988 , p. 53). The only possible steady state is one in which the actual rate of utilisation is equal to its normal or targeted level. This leads to the belief that the only consistent steady-state analysis is one where those two rates are equal, i.e., what Vianello and others consider to be 'fully adjusted positions'.

This is an embarrassing objection to the Kaleckians.' If the actual rate of capacity must eventually be equal to a given normal rate, then the rate of utilisation is not an endogenous variable in the long period any more. The objection is particularly valid since Kaleckians have sometimes referred to the normal rate as the 'planned' degree of utilisation of capacity (Steindl, 1952, p. 129; Amadeo, 1986B, p. 83), thus reinforcing the belief that the normal rate of capacity utilisation is a target of firms, which must be fulfilled in the long period. The complications arising from such an interpretation can be clearly spelled out by using an investment function suggested by Steindl (1952, p. 128) and reintroduced by Amadeo (1986A, 1986B). This investment function is based on the distinction between undesired and desired excess capacity, or between the actual rate and the normal rate of capacity utilisation, respectively denoted by $u$ and $u_{n}$.

$$
g^{2}=\gamma+g_{u}\left(u-u_{n}\right)
$$

The investment function is illustrated in Fig. 4, where the actual rate of accumulation is to be found at the intersection of the $g^{i}$ and the $g^{k}$ curves. ${ }^{2}$ If the actual rate of utilisation turned out to be equal to the normal or desired one, the actual rate of growth would be equal to $\gamma$. As Committeri (1986, p. 173) and Caserta (1990, p. 152) point out, if firms are content with the degree of capacity utilisation that is being achieved and do not desire to have it changed, one concludes that the rate of accumulation desired by firms should be equal to the expected growth rate of sales. It is clear from equation (30) that the exogenous parameter $\gamma$ then represents this expected growth rate of sales. If, as is shown on the graph, it is assumed that the actual rate of capacity utilisation $u_{1}$ is smaller than the planned rate $u_{n}$, the actual rate of growth $g_{1}$ must be smaller than the expected growth rate of sales $\gamma_{1}$. Committeri argues that this cannot be a consistent solution: in a proper steady-state model, expectations of sales growth and of spare capacity should be realised.

\footnotetext{
${ }^{1}$ Halevi and Kriesler (1991) and Sawyer (1994) also come to grip with that objection.

${ }^{2}$ Note that the $g$ curve is identical to the profits cost function, equation (13), except for a muluplicative constant arising from the savings function, equation $(18)$, such that: $g^{\prime}=s_{p}[u(m / v)-(1-m) f / v]$.
} 


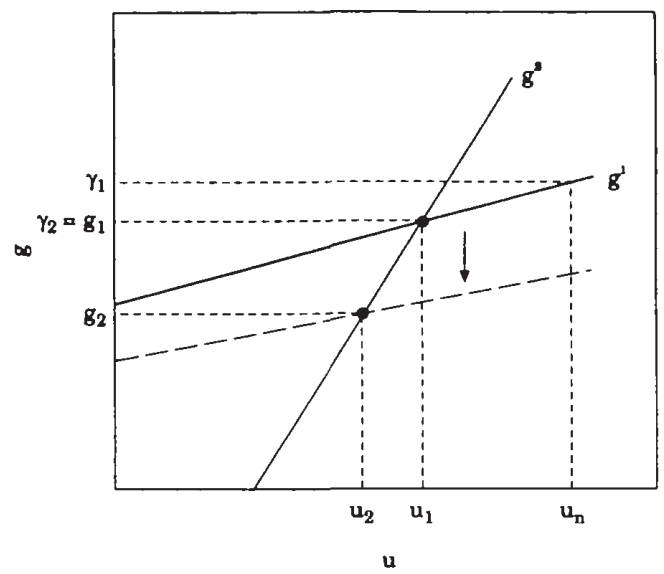

Fig. 4. Firms revise the expected rate of sales growth, at a constant standard rate of capacity urlization: instability.

At this stage, four possibilities arise: firms take into account this divergence between actual and expected rates of growth of sales in their investment function; firms revise their expectations of sales growth; firms revise their targeted normal rate of capacity utilisation; firms revise both their expectations of sales growth and their normal rate of utilisation. All four possibilities will be dealt with.

Taking the expected growth rate of sales into account

Suppose first that firms incorporate the discrepancy between sales expectations and realisation within the investment function. Investment function (30) would now be:

$$
g^{i}=\gamma+\alpha(g-\gamma)+g_{u}\left(u-u_{n}\right)
$$

Capital accumulation would accelerate whenever the actual growth rate of sales exceeds their expected growth rate $\gamma$. Such a function is proposed by Eichner (1976, p. 197), to take into account the fact that the actual growth rate may diverge from the secular growth rate, and hence says Eichner, from the expected growth rate. Such a function, however, adds little to the existing model. There still will be steady-state positions where expectations and targets are not being realised. This can be seen by solving equation (31) and verifying that it contains all the features of equation (30):

$$
g^{\prime}=\gamma+g_{u}\left(u-u_{n}\right) /(1-\alpha)
$$

The second possibility is the one underlined by Committeri and Kurz. Firms could react to their unrealised sales expectations by modifying their expectations of sales growth. The $\gamma$ coefficient would then vary according to the realised values of the rate of growth. If firms react in an adaptive manner, the expected growth rate of sales at each period would then be:

$$
\gamma_{t}=(1-\varphi) \gamma_{t-1}+\varphi g_{t-1} \quad 0<\varphi<1
$$

In the case depicted in Fig. 4, the $\gamma$ coefficient would go down to $\gamma_{2}$. This implies that the investment curve $g$ s should shift down, the actual rate of growth should drop to $g_{2}$, and the actual and normal rates of utilisation of capacity should diverge even further. The 


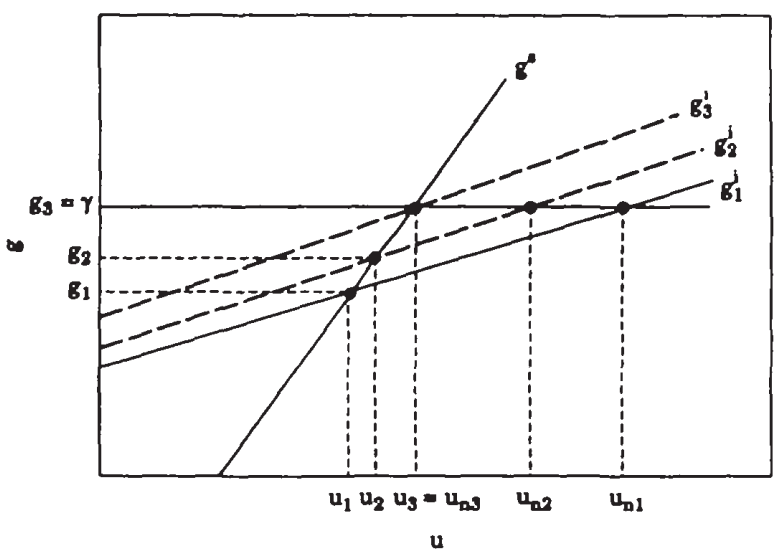

Fig. 5. Firms revise the standard rase of capacity untizacion, at a constant expected rate of sales growth: stability.

conclusion of this exercise, if the normal rate of utilisation of capacity is considered to be a target and if firms respond to their unrealised sales expectations, is that the model is unstable (Committeri 1986, p. 175). As Kurz (1994, p. 415) points out, this is reminiscent of Harrod's instability principle. There is no fully adjusted position besides full capacity utilisation, or else it must be assumed that the rate of utilisation in the long-period position is always equal to its normal level.

Revising the normal rate of capacity utilisation

The third possibility that arises from considering the normal rate of capacity utilisation as a target rate is the following: one would expect the target to change according to historical variations in the actual rate. The normal rate of utilisation $u_{n}$ ceases to be an exogenous variable that contributes to determine the actual utilisation and accumulation rates. This was recognised early on by Amadeo (1986A, p. 155) and Ciccone (1986, p. 35). Of course it may be said that if the normal rate of urilisation tends towards the actual rate of utilisation, the steady-state rate of utilisation is still endogenous, although in the fully adjusted position the normal and the actual rates are necessarily equal.

In this third case, it will be supposed that the expected rate of growth of sales $\gamma$ is an expectation based on unchanging secular trends-a somewhat unKaleckian assumption. ${ }^{1}$ Investment equation (30) thus depends on the perceived secular growth rate of sales, i.e., it does not depend on the actual growth rate: $\gamma$ is a given, in contrast to what has just been assumed in the Harrodian instability case. Let us also suppose that the normal rate of capacity utilisation responds to the actual rate of capacity utilisation in the following manner:

$$
u_{n(1)}=(1-\tau) u_{m(1-1)}+\tau u_{(x-1)} \quad 0<\tau<1
$$

The fully adjusted impact of the above two assumptions can be observed in Fig. 5. Let us start, as in Fig. 4, from a situation where the initial rate of growth $g_{1}$ is below $\gamma$, and hence where the rate of capacity utilisation $u_{1}$ is below the normal rate $u_{n 1}$. This will

' It should be pointed out that a similar assumption is required for the stability of multi-sector growth models that study the possibility of classical gravitation: investment depends on a given steady-state rate of growth $\gamma$, which is supposedly known (Caminati, 1990, p. 24). 
induce a fall in the normal rate of capacity utilisation, along the lines of equation (34), say to $u_{n 2}$. This fall in the normal rate of capacity utilisation will in turn induce an upward shift of the investment function $g$. The new actual rate of capacity utilisation $u_{2}$ will now be higher than the previous actual rate $u_{1}$, and it will be closer to the normal rate of capacity utilisation, while the new rate of accumulation $g_{2}$ will also be higher. This process will continue until the actual and the normal rates of capacity utilisation, $u_{3}$ and $u_{n 3}$, converge with each other, at which point the rate of growth of the economy will be exactly equal to $\gamma$. In such a model, there is thus a convergence towards the expected secular growth rate of sales: as Committeri $(1986$, p. 174) would have it, producers 'would be content with what they are doing'. This would also be reflected in the long-period equality between the actual and the normal rates of utilisation. Despite this equality, however, the rate of utilisation is still endogenous.

The value of the fully adjusted rate of capacity utilisation depends on the expected secular rate of growth $\gamma$ and on the parameters defining the $g^{2}$ curve, in particular the margin of profit and the propensity to save. While the rate of utilisation is endogenous, many of the properties of the canonical Kaleckian model do not hold any more. There is still a positive relationship between the animal spirits of the entrepreneurs (the $\gamma$ parameter) and the rates of accumulation, profit and utilisation. However, the paradox of cost and the paradox of thrift only hold in a degenerate version. An increase in real wages has no impact on the fully-adjusted rate of accumulation and its rate of profit, although it will induce a higher rate of capacity utilisation; similarly, a decrease in the propensity to save has no impact on the rate of accumulation, although it will induce higher rates of profit and of utilisation. The rate of accumulation in the fully adjusted position is not endogenous any more. The model thus contains a mix of Kaleckian and neo-Ricardian features.

\section{A possibility devoid of definite solutions}

One need not assume, however, that the expected rate of growth is given to safeguard the Kaleckian model. Both the expected growth rate of sales $\gamma$ and the normal rate of utilisation $u_{n}$ may react to discrepancies with their realised values, in accordance with equations (33) and (34). This is the fourth possibility: it would deprive the model of definite solutions, since there would be no point of anchor for the model, but all the usual Kaleckian results could be restored. Whether stability or instability prevails in such a model would depend on the relative speed with which $\gamma$ and $u_{n}$ would react. Since the adaptive behaviour of the normal rate of utilisation provided stability (the third case), whereas the adaptive behaviour of the expected growth rate brought instability (the second case), intuition tells us that a necessary condition for the stability of this fourth case is that $\tau$ be larger than $\varphi$.

Let us illustrate this fourth case with the help of Fig. 6. Let us assume that initially, through luck or the adjustment mechanism to be described, the economy is in a steady-state where the actual rate of accumulation of the economy is equal to the expected growth rate of sales $\gamma_{1}$, and where the actual rate of utilisation is equal to its normal rate $u_{n 1}$. This is given by the intersection of the curves denoted by $g_{1}{ }_{1}$ and $g_{1}^{3}$. Suppose there is now an increase in real wages, or a fall in the propensity to save. This implies that the savings curve shifts to the right, from $g_{1}^{*}$ to $g_{2}{ }_{2}$. The new steady-state rate of accumulation and rate of capacity utilisation will now be higher, at $g_{2}$ and $u_{2}$. Because these rates are not equal to their target values, such a situation cannot last. The adjustment mechanisms described by equations (33) and (34) will now come into play. 


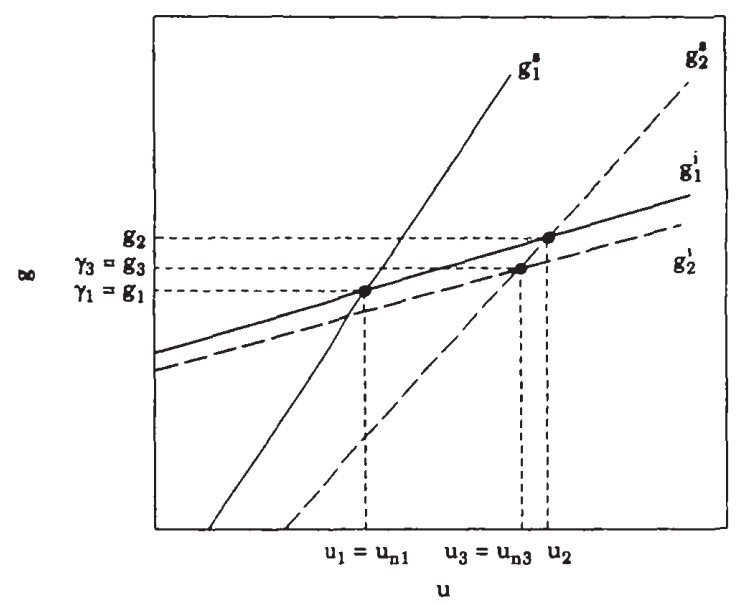

Fig. 6. Fims revise both the scandand rate of capacty unlization and the expected rate of sales growth

Both the expected growth rate $\gamma$ and the normal rate of utilisation $u_{n}$ will rise, and consequently shift the investment function.

The crucial question is whether the $g^{\prime}$ curve will shift up or down. This depends, as can be seen from equation (30), on whether the change in desired accumulation induced by the increase in the normal rate of utilisation, $-g_{u} \mathrm{~d} u_{n}$, will surpass the change in desired accumulation induced by the increase in the expected growth rate of sales, $+\mathrm{d} \gamma$. If the expected growth rate of sales is the more sensitive to actual values, the $g$ curve will shift up and instability will sway the model. If the normal rate of capacity utilisation is the more sensitive, the $g^{\prime}$ curve will shift down to $g_{2}$, as illustrated in Fig. 6 , and stability will prevail.' This adjustment mechanism will continue until finally the normal and the actual rates of utilisation are equated at $u_{n 3}$, at which point sales growth expectations and the rate of accumulation will also be equated $\gamma_{3}$. The fully adjusted position will lie somewhere on the $g_{2}$ curve, between $g_{1}$ and $g_{2}$. The revised model is thus deprived of a definite solution; rather there exists a set of possible solutions.

The fourth possibility in its stable incarnation thus offers some middle ground between Kaleckians and their critics. On the one hand, the actual rate of capacity utilisation is necessarily equal to its normal value in the fully adjusted position, as many critics would have it. The normal rate of utilisation is, however, itself endogenous across long-period positions. All the standard Kaleckjan results follow from this endogeneity of the actual and normal rates of utilisation. In particular, as shown on Fig. 6, the paradoxes of cost and of thrift both hold. Starting from a fully adjusted position, an increase in the real wage rate, or a decrease in the propensity to save, induces higher rates of profit and of accumulation in the new fully adjusted position. While fully adjusted positions are associated with normal values of the rate of capacity utilisation, this does nqt imply that the wage-profit curve is given for different fully adjusted positions, even though techniques are given.

${ }^{1}$ More exactly the stability of the adjustment process requires $\tau\left(\gamma w / s_{p}+A\right)>\varphi\left(\gamma / g_{u}+A\right)$, where $A=(1-m) f-m u_{*}$. This implies, given stabulity condition (21), that $\tau>\Phi$ is an insufficient condition. 
Following a suggestion by Dutt, Amadeo properly described the proposed adjustment mechanism, but without a graphical illustration.

Indeed, one may argue that if the equilibrium degree is systematically different from the planned degree of utilization, entrepreneurs will eventually revise their plans, thus altering the planned degree. If, for instance, the equilibrium degree of utilization is smaller than the planned degree $\left(u^{\star}<u_{n}\right)$, it is possible that the entrepreneurs will reduce $u_{n}$. The reduction of the planned degree would shift the investment function in such a way that the new equilibrium degree will be greater than the initial one. If entrepreneurs keep revising their plans, eventually both degrees of utilization will coincide. Even if this is the case, however, the objective of this model is to show that the equilibrium degree of utilization-be it equal to or different from the planned degree-is endogenously determined. (Amadeo, 1986A, p. 155)

To preserve the endogenous determination of the rate of utilisation within fully adjusted positions, one must thus argue that the adjustment of the normal rate of capacity utilisation occurs faster than any possible adjustment of the expected growth rate of sales. This is actually the position taken by those neo-Ricardian who favour an endogenous rate of utilisation in the long period. For instance, while Ciccone believes that 'the effectively experienced utilization of capacity influences the utilization considered normal only very slowly' (1986, p. 36), he points out that in his analysis the rate of accumulation is an 'independent given' (1987, p. 109). Similarly, when discussing Ciccone's model, Committeri (1986, p. 179) speaks of 'a secular path of accumulation' that would be little affected by fluctuations in demand.

\section{The convergence towards normal rates of profit and of utilisation and the pricing equation}

The normal rate of utilisation and target return pricing

Up to now the analysis has emphasised the shape of the investment function. It was, however, mentioned in Section 1 that the target rate of return and the standard degree of capacity utilisation have an impact on pricing, and hence on the profits cost function. Let us assume in the following that the normal rate of profit about which the neo-Ricardians are talking is no different from the target rate of return or the standard rate of profit used in target return pricing, and that the normal rate of capacity utilisation is the same concept as the standard rate of capacity utilisation. ${ }^{1}$ This will allow us to formalise some neo-Ricardian objections to the Kaleckian model of growth and distribution, focusing this time on the pricing decision and on the normal rate of profit. Let us start with a long quote by one of these neo-Ricardian critics:

The possibility of capacity utilization being different from its planned degree in the long run would have an important implication for theories of distribution and accumulation... The realized rate of profit emerging from the interplay between distribution and effective demand may not be inversely related to the real wage, even in situations that the authors seem not to think limited to the short period; another way to say this is that the . . normal rate of profit $r_{\text {m }}$ (i.e. the rate of profit technically obtainable at the normal utilization degree with [the real wage rate] taken at its current level) may diverge from its realized rate, even for long periods of time. Now, we do not wish to quarrel with this reasonable proposition: the observed rate of profit is very unlikely to coincide with $r_{w}$ even in terms of averages covering long periods of time, although we might suspect that after all, there must exist some connection between the two rates. The model, however, contains no element

'As noted by Reynolds (1987, p. 179), 'the target rate of return can possibly be thought as corresponding to the long-run rate of profit, as in Sraffa's model'. 


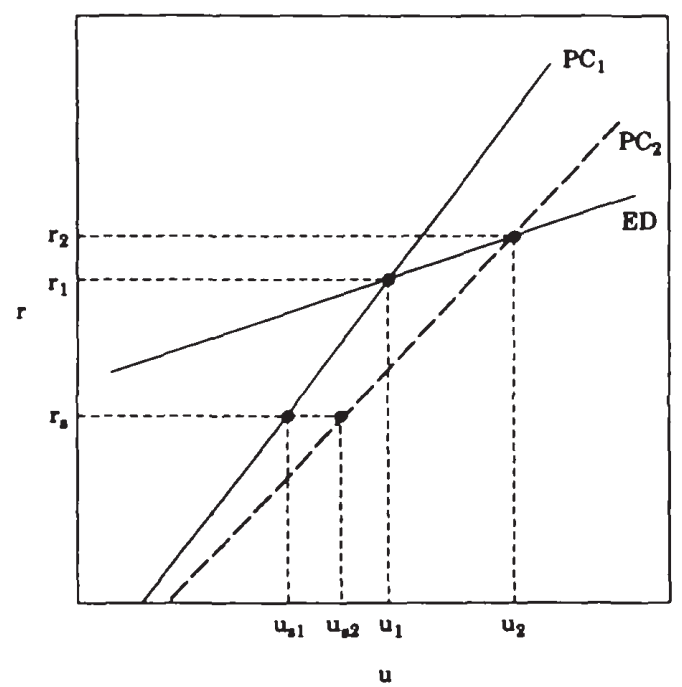

Fig. 7. Furms nevise the standard rate of capacity uralization in the pncing formula: instabihty.

for the exploration of this connection, as it implies a persistent and systematic divergence berween [the actual and the normal degree of capacity utilization]. (Committeri 1986, pp. 170-171)

Committeri's critique of the Kaleckian growth model is the macroeconomic version of the objection addressed towards multi-sector pricing models based on a vector of exogenous target rates of retum (Boggio 1992, p. 284). How are those rates supposed to be determined? Should not a complete long-period theory include an explanation of how they are formed or modified? We first deal with the standard rate of capacity utilisation and then with the target rate of return.

Let us go back to equation (16), which represents the profits cost function set in the context of target return pricing procedures. Let us now deal with a change in the standard rate of capacity utilisation which figures in the pricing formula. An increase of this standard rate is equivalent to a reduction of the margin of profit, and its implies an increase in the real wage rate. It follows that an increase of the standard rate of utilisation of capacity must be associated with a downward shift of the profits cost curve. This is illustrated in Fig. 7. The initial profits cost curve is $\mathrm{PC}_{1}$, to which corresponds a standard rate of utilisation of capacity $u_{s 1}$ and a target rate of return $r_{s}$. The effective demand curve being assumed given, that is the investment function is of the usual Kaleckian type (equation 19), the actual utilisation and profit rates in the initial situation are $u_{1}$ and $r_{1}$ respectively. In the situation drawn, the actual rate of utilisation exceeds its standard level, and hence so does the actual rate of profit. Let us suppose that firms react to this discrepancy by changing the standard rate of utilisation contained in the target return pricing formula, according to the formula given by equation (34), $u_{s}$ here playing the role of $u_{n}$. What is to be shown is that tampering with the standard rate of utilisation of capacity in the pricing equation will resurrect Harrod's instability problem.

Suppose that as a result of the high actual rate of utilisation, the new standard rate of capacity utlisation incorporated in the pricing formula is raised from $u_{s 1}$ to $u_{s 2}$. Let us 
further assume that the standard rate of profit is left unchanged. It can be seen in Fig. 7 that the new actual rate of utilisation $u_{2}$ will be even larger than in the previous period, while the discrepancy between the actual rate of profit and its standard rate has grown even larger, to $r_{2}-r_{s}$. Letting the standard rate of utilisation of capacity respond to the fluctuations in its current rate thus exacerbates the overuse or the lack of use of capacity. Of course, there is an upward limit to this phenomenon: the rate of utilisation can be no higher than unity; but no such limit exists on the downward side. We are back to the conclusions drawn by Committeri in the unstable case of the investment function; the model is unstable, or the degree of capacity utilisation must be assumed to be equal to unity or to its normal rate.

One is tempted to conclude that the standard rate of utilisation of capacity is a purely conventional parameter, because it cannot be otherwise for structural macroeconomic reasons. If price makers were to revise their view of the standard rate of capacity utilisation according to the values taken by the actual rate, the economy would be highly unstable. Indeed it is well known that firms that employ target return pricing hardly ever change the standard rate of utilisation that is present in cost-plus pricing procedures. For instance, until the events of the last decade, the standard rate of utilisation of capacity incorporated in the pricing formula used by GM underestimated the rate of utilisation that was actually realised in most years by the company. As a consequence, 'the realized return on invested capital has averaged well over the 15 per cent target rate' (Scherer, 1970, pp. 174-175).

\section{The normal rate of profit and target return pricing}

Let us now deal with changes in the target rate of return, i.e., the standard rate of profit $r_{s}$. It is clear from equation (15) that an increase in the standard rate of profit leads to a rise in the profit margin $m$. It is equally clear from equation (16) that the profits cost curve shifts up when the standard rate of profit $r_{s}$ is increased in the target return pricing formula. It is at this juncture, it seems, that the arguments in favour of the inverse relationship between real wages and accumulation are the strongest. If firms respond to the overutilisation or to the underutilisation of capacity in the manner described by orthodox theory, that is by lowering prices in the latter case and by raising them in the former, the possible range of the actual rate of utilisation in the long period should be smaller than if the gross margin of profit is truly exogenous. ${ }^{1}$ If firms diminish the target rate of return whenever the actual rate of profit exceeds the standard rate, the possible range of the actual rate of capacity utilisation would be diminished to the point of uniqueness: in the fully adjusted position, the actual rate of capacity utilisation could only be equal to its standard rate. Let us then suppose that firms react to a discrepancy between the actual and the standard rate of profit, and set the target rate of return in the following manner:

$$
r_{s(v)}=(1-\mu) r_{s(t-1)}+\mu r_{(t-1)} \quad 0<\mu<1
$$

Combining equations (35) and (15), we see that whenever the rate of profit exceeds the target rate of return, firms react by increasing the target rate of return and the margin of profit. What happens is illustrated in Fig. 8. The effective demand curve and the

\footnotetext{
' Similarly, Sawyer (1994, p. 220) and Garegnani (1992, p. 70) argue that the propensity to save s, is not a constant: with high rates of accumulation firms tend to retain a higher proportion of their earnings. This compensates for the favourable impact of the rate of accumulation on the actual profit rate, and as a result the fluctuations of the actual profit rate around the normal rate would be dampened.
} 


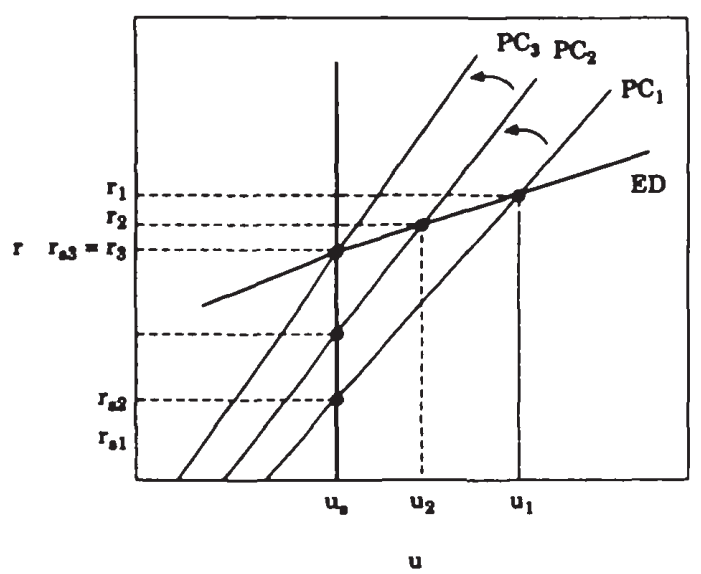

Fig. 8. Firms revise the target rate of retum in the pricing formula: stablhty.

standard rate of utilisation of capacity are assumed to be given. Let us start from a situation where the profits cost curve is $\mathrm{PC}_{1}$, corresponding to a low target rate of return $r_{s 1}$. Under this situation, both the actual rate of profit and the actual rate of urilisation are high, at $r_{1}$ and $u_{1}$. This situation will not last as firms revise the target rate of return, moving it up from $r_{s 1}$ to $r_{s 2}$. The profits cost curve shifts to $\mathrm{PC}_{2}$, yielding a rate of profit that is still higher than the standard rate, but where the difference between the two is now smaller than initially. This process will go on until the target rate of return is set at a level of $r_{s 3}$, at which point the actual rate of profit will be equal to it, while the rate of utilisation will be equal to its standard rate $u_{s}$. Note that changes in the target rate of return induced by the actual levels of the rate of profit tend to stabilise the model. An increase in the target rate of return, caused by an excess of the actual rate of profit over the standard rate, pulls down both the actual rate of profit and the actual rate of utilisation.

The rate of utilisation can only be an endogenous variable in the long period if the adjustment of the target rate of return to the actual conditions is sluggish, and preferably non-existent. This is all too evident in pricing equation (17), where it is obvious that the standard and actual rates of utilisation are equal if the standard and actual rates of profit are equated. If there exists a process insuring this latter equality, the actual rate of utilisation in the fully adjusted position becomes a predetermined variable, equal to the given conventional standard rate. The various cost and reaction parameters being given, the standard rate of utilisation of capacity thus determines the rate of profit that is consistent with it, through the effective demand function. This determines then the real wage rate and the rate of growth. The neo-Ricardian causal nexus presented in Section 2 and in Fig. 2 has been brought back. Furthermore, the inverse relationship between the rate of growth and the real wage rate that characterised earlier neoKeynesian models is recovered. Because the rate of utilisation is given, an increase in the exogenous determinants of the growth rate-the expected secular growth rate that Eichner talks about-induces an increase in the rate of profit and a fall in the real wage. This is represented in Fig. 9 by an initial upward shift of the effective demand curve, from $\mathrm{ED}_{1}$ to $\mathrm{ED}_{2}$, due to an increase in the $\gamma$ parameter. This is followed by an induced upward shift of the profits cost curve, from $\mathrm{PC}_{1}$ to $\mathrm{PC}_{2}$, corresponding to a hike 


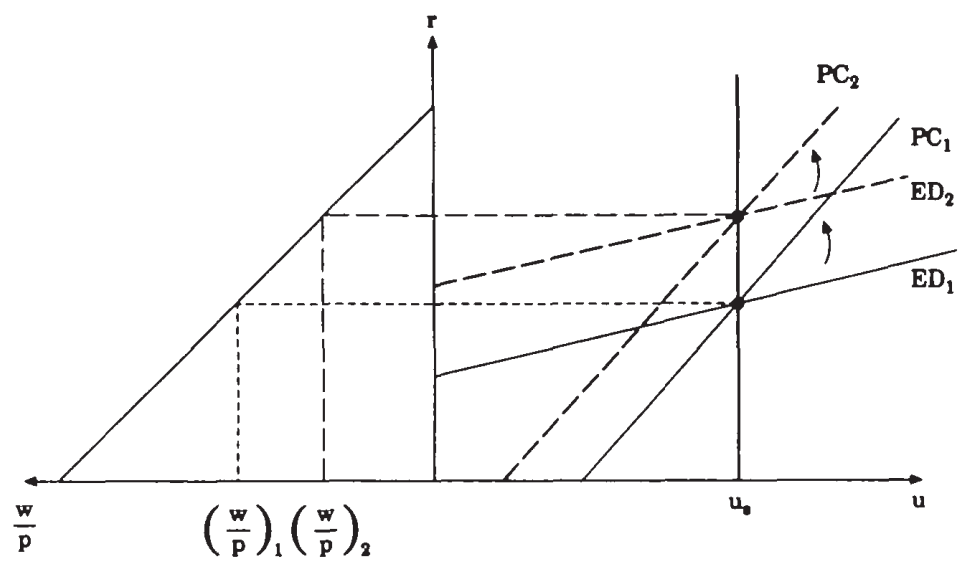

Fig. 9. The Eichner-Woad-Cambridge variant of the classical case.

in the margin of profit. At the end of the process, the rate of growth and the rate of profit have risen, but the real wage rate has fallen, as they would have in the neo-Keynesian model.

Thus, as Marglin (1984, p. 125) correctly points out when discussing the neoKeynesian model, 'the key assumption is that the rate of capacity utilisation varies on the path between steady-growth configurations, but not across steady-growth states'. In the present terminology, the rate of capacity utilisation varies between long-period positions, but not across fully adjusted positions.

It should be noted that the results arrived at with the help of equation (35) are very similar to the story provided by Eichner $(1976,1987)$ and other post-Keynesians who have emphasised the financial needs of investment growth and their effect on the profit margin of corporations. ${ }^{1}$ In those models, a faster pace of investment induces firms to increase their margin of profit in search of additional internal funds to finance this investment. In the Eichnerian model, as in the earlier neo-Keynesian models of Kaldor and Robinson, increased investment is associated with higher prices relative to wage unit costs. Effective demand and growth rates have an impact on margins of profit. For those authors, while in the short period the actual and the standard rates of capacity utilisation may diverge, it is not so in the long period. The reason for this is that they assume that the standard rate of profit will be adjusted to the actual trend of the growth rate, and hence to the actual rate of profit, as in Fig. 9. This leads Wood (1975, p. 129), for instance, to say that his model is a 'long run model of the determination of the share of profits at normal full capacity use'. The requirement of a normal rate of capacity utilisation implies, however, that faster accumulation is inexorably linked to lower real wages and disposable income (Eichner 1976, pp. 278-279). By contrast, in the Kaleckian model, an increase in the exogenous determinants of the growth rate is conducive to faster accumulation without real wages changing, while higher real wages are conducive to faster accumulation. The relation between real wages and the accumulation rate is thus reversed in the Eichnerian model when compared to that of the

1 We may include the models proposed by Wood (1975) and Harcourt and Kenyon (1976) among the Eichnerian models. See Nell (1992, ch. 17) for a detailed critique of each of these Eichnerian models. 


\section{M. Lavoie}

Kaleckian model (Agliardi, 1988). The opposition is striking, since the Elchnerians and the Kaleckians equally rely on firms setting prices within an oligopolistic industrial structure.

The above analysis thus shows that to insist on realised targets gives full justification to the position taken by many neo-Ricardian authors. If an adjustment mechanism equates the actual rate of profit and the target rate of return, normal prices eventually prevail, and the long-period inverse relation between the real wage rate and the rate of accumulation must also prevail.' This inverse relation is upheld despite the presence of all the standard Kaleckian features.

It could be possible to argue, however, along the lines presented when discussing Fig. 6, that both the standard rate of utilisation and the standard rate of profit of the target pricing formula could respond to actual values. One would again obtain a model without definte solutions, but where, in the stable case, higher real wages in fully adjusted positions could be associated with higher rates of accumulation and higher rates of profit, despite the actual rates of profit and of capacity utilisation being equal to their standard values.

Another avenue, which would add a Kaleckian formalisation of inflation and real wage determination to the present model, could also have been pursued to retain all the radical results of the Kaleckian model. It has been shown by Lavoie (1992, pp. 417-421) that the addition of a conflicting-claims theory of inflation drives a wedge between the target rate of return assessed by firms $\left(r_{s}^{\star}\right)$ and the target rate of return actually incorporated into prices $\left(r_{s}\right)$. Within such a model, the adjustment mechanism described by equation (35) equates the actual rate of profit with the target rate of return assessed by firms $\left(r=r_{s}^{\star}\right)$, but not with the target rate of return incorporated into prices $\left(r \neq r_{s}\right)$. It follows, in contrast to the belief of many neo-Ricardians (Ciccone, 1987, p. 110), that even in fully adjusted long-period positions, actual prices are not equal to normal prices, i.e., those prices that would bring into equality the target rate of return incorporated into prices and the actual rate of profit if the economy were operating at normal capacity. ${ }^{2}$ As a consequence, the rate of capacity utilisation is still free to vary from its standard or normal rate. The key characteristics of the Kaleckian model, that is, the endogeneity of the rate of utilisation of capacity, in the short period, in the long period and in fully adjusted positions, is preserved within a model with definite solutions.

\section{Conclusion}

The main features of the Kaleckian model of growth and distribution have been shown to be based on its pricing equation, its investment function and the endogeneity of the rate of capacity utilisation. In particular, the model has been extended to a pricing procedure based on target return pricing. It has been demonstrated that the neo-Marxian critique of the investment function is very similar to the neo-Ricardian objections to the same investment function. Various arguments have been advanced to justify the particular investment function put forth by Kaleckians, despite the logic of the criticisms.

\footnotetext{
' Normal prices preval in this simple one-sector world. Boggio (1986) has shown that in multi-sector models of target retum pricing, cost-plus prices with an arbitrary vector of target rates of return also converge towards normal prices with a uniform rate of profit, when the target rates of retum slowly respond to demand conditions Such a model, however, contains none of the so-called Keynesian features present in our Kaleckian model.

${ }^{2}$ Note that Boggio (1992, p. 287) comes to a similar conclusion within the context of a multi-sector model: with inconsistent claims between workers and firms, the vector of actual profit rates is not equated to the vector of target rates of return in the long period.
} 
It has also been shown that the Kaleckian model, when overhead labour costs are included, is impervious to the criticism that it does not fit the recent stylised facts.

The notions of normal (or standard) rate of capacity utilisation and of normal (or standard) rate of profit have also been extensively discussed, since the inequality between those two rates and the long-period solutions of Kaleckian models has come under heavy criticism, mainly from neo-Ricardian authors but also from other non-orthodox economists. The main issue is whether the normal rate of utilisation or the normal rate of profit must be seen as target variables that firms endeavour to realise. In the case of the investment function, it has been shown that the normal rate of capacity utilisation can be slowly revised according to its own actual rate without the model losing all of its Kaleckian characteristics. This requires, however, that the expected growth rate of sales, imbedded in some Kaleckian investment functions, remain given or adjust even more slowly than the normal rate of utilisation to actual conditions. In the latter case, although the actual rate of capacity utilisation ends up equating the normal rate of utilisation, the positive relation berween the real wage rate and the rate of accumulation is sustained in fully adjusted positions. Such a surprising result is due to the fact that both the actual and the normal rates of utilisation are endogenous across fully adjusted positions, so that the wage-profit frontier at the normal rate of utilisation is not fixed any more. The drawback of this formalisation, however, is that the model is left with a set of solutions, rather than a definite one. Furthermore, if the expectations of sales growth are quickly modified in reaction to the actual rates of growth, the model becomes unstable.

Looking now at the pricing part of the model, it was shown that the normal rate of utilisation cannot respond to the actual rate of utilisation, otherwise the model once more becomes unstable. On the other hand, the normal rate of profit may respond to the actual rates of profit without disturbing the stability of the model. As some critics have already noted, however, such an adjustment mechanism makes exogenous the rate of capacity utilisation, and consequently it destroys the Kaleckian positive relation between the real wage rate and the rate of accumulation. Such a model behaves more like the neoKeynesian model of Robinson and Kaldor, showing features akin to Eichnerian growth models. The positive relation between real wages and accumulation is, however, recovered when one adds to the model a conflicting-claims theory of inflation and real wage determination.

In view of the analysis pursued in this paper, and in view of the results obtained with regard to the convergence of full cost prices towards production prices, we may now assert that pure production prices must be seen as the notional version of the more realist cost-plus prices. One would agree with Boggio (1990, p. 57) that 'the most promising way forward, in terms both of realism and of definiteness of results, is to develop the full-cost models'.

\section{Bibliography}

Agliardi, E. 1988. Microeconomic foundations of macroeconomics in the post-Keynesian approach, Metroeconomica, vol. 39, no. 3, 275-297

Amadeo, E. J. 1986A. The role of capacity utilization in long-period analysis, Political Economy, vol. 2, no. 2, 147-185

Amadeo, E. J. 1986B. Notes on capacity utilization, distribution and accumulation, Contributions to Political Economy, vol. 5, 83-94

Amadeo, E. J. 1987. Expectations in a steady-state model of capacity utilization, Political Economy, vol. 3, no. 1, 75-89 
Asimakopulos, A. 1975. A Kaleckian theory of income distribution, Canadian foumal of Economics, vol. 8, no. 3, 313-333

Auerbach, P. and Skott, P. 1988. Concentration, competition and distribution, International Review of Apptied Economics, vol. 2, no. 1, 42-61

Bhaduri, A. and Marglin, S. 1990. Unemployment and the real wage: the economic basis for contesting political ideologies, Cambridge foumal of Economics, vol. 14, no. 4, 375-393

Blecker, R. A. 1989. Internstional comperition, income distribution and economic growth, Cambridge foumal of Economics, vol. 13, no. 3, 395-412

Boggio, L 1986. Stability of production prices in a model of general interdependence, in Semmler, W. (ed.), Competition, Instability, and Nontinear Cycles, Berlin, Springer-Verlag

Boggio, L. 1990. The dynamic stability of production prices: a synthetic discussion of models and results, Potitical Economy, vol. 6, no. 1-2, 47-58

Boggio, L. 1992. Production prices and dynamic stability: results and open questions, Manchester School of Economic and Sactal Studies, vol. 60, no. 3, 264-294

Caminati, M. 1990. Gravitation: an introduction, Political Economy, vol. 6, no. 1-2, 11-44

Caserta, M. 1990. The steady-state model of capital utilisation: a comment, Studi Economica, vol. $41,139-153$

Chamberlain, T. W. and Gordon, M. J. 1989. Liquidity, profitability, and long-run survival: theory and evidence on business investment, foumal of Post Keynesian Economics, vol. 11, no. 4, $589-610$

Ciccone, R. 1986. Accumulation and capacity utilization: some critical considerations on Joan Robinson's theory of distribution, Political Economy, vol. 2, no. 1, 17-36

Ciccone, R. 1987. Accumulation, capacity utilization and distribution: a reply, Political Economy, vol 3, no. 1, 97-111

Committeri, M. 1986. Some comments on recent contributions on capital accumulation, income distribution and capacity utilization, Political Economy, vol. 2, no. 2, 161-186

Committeri, M. 1987. Capacity utilization, distribution and accumulation: a rejoinder to Amadeo, Political Economy, vol. 3, no. 1, 91-95

Del Monte, A. 1975. Grado di monopolio e sviluppo economico, Rivista Intermazionale di Screnze Sociali, vol. 83, no. 3, 231-263

Dumenil, G. and Lévy, D. 1987. The dynamics of competition: a restoration of the classical analysis, Cambridge foumal of Economics, vol. 11, no. 2, 133-164

Dutt, A. K. 1984. Stagnation, income distribution and monopoly power, Cambridge Joumal of Economics, vol. 8, no. 1, 25-40

Dutt, A. K. 1990. Growth, Distribution and Uneven Development, Cambridge, Cambridge University Press

Dutt, A. K. 1992A. Conflict inflation, distribution, cyclical accumulation and crises, European foumal of Political Economy, vol. 8, 579-598

Dutt, A. 1992B. Rentiers in Post Keynesian Models, in Arestis, P. and Chick, V. (eds), Recent Developments in Post-Keynesian Economics, Aldershot, Edward Elgar

Eichner, A. S. 1976. The Megacorp and Oligopoly: Micro Foundations of Macro Dynamics, Cambridge, Cambridge University Press

Eichner, A. S. 1987. The Macrodynamics of Aduanced Market Economies, Ammonk, M. E. Sharpe

Epstein, G. 1994. A political economy model of comparative central banking, in Dymski, G. and Pollin, R. (eds), New Perspectives in Monetary Macroeconomics, Ann Arbor, University of Michigan Press

Fazzari, S. M. and Mott, T. L. 1986-87. The investment theories of Kalecki and Keynes: An empirical study of firm data, 1970-1982, foumal of Post Keynesian Economics, vol. 9, no. 2, 171-187

Garegnani, P. 1992. Some notes for an analysis of accumulation, in Halevi, J., Laibman, D. and Nell, E. (eds), Beyond the Steady State: A Revival of Growth Theory, London, Macmillan

Halevi, J. and Kriesler, P. 1991. Kalecki, classical economics and the surplus approach, Rerrew of Political Economy, vol. 3, no. 1, 79-92

Harcourt, G. C. and Kenyon, P. 1976. Pricing and the investment decision, Kyklos, vol. 29, no. 3, 449-477

Kaldor, N. 1957, A model of economic growth, Economic foumal, vol. 67, 591-624 
Kaleck, M. 1971. Selected Essays in the Dynamics of the Capitalist Economy, Cambridge, Cambridge University Press

Kurz, H. D. 1986. Normal positions and capital utilization, Patitical Economy, vol. 2, no. 1, 37-54

Kurz, H. D. 1990. Effective demand, employment and capital utilisation in the short run, Cambridge foumal of Economics, vol. 14, 205-217

Kurz, H. D. 1991. Technical change, growth and distribution: a steady state approach to unsteady growth on Kaldorian lines, in Nell, E. J. and Semmler, W. (eds), Nicholas Kaldor and Mainstream Economics, London, Macmillan

Kurz, H. D. 1993. Accumulation et demande effective: quelques notes, Cahiers d'économie palitique, vol. $22,59-82$

Kurz, H. D. 1994. Growth and distribution, Review of Political Economy, vol. 6, no. 4, 393-421

Lavoie, M. 1992. Foundations of Post-Keynesian Economic Analysis, Aldershot, Edward Elgar

Lavoie, M. 1995. Interest rates in post-Keynesian models of growth and distribution, Metroeconomica, vol. 46 , no. $2,146-177$

Lanzillotti, R. F. 1958. Pricing objectives in large companies, American Economic Review, vol. 48, no. 5, 921-940

Lee, F. S. 1985 . Full cost prices, classical price theory, and long period method analysis: a critical evalustion, Metroeconomica, vol. 37, no. 2, 199-219

Marglin, S. A. 1984. Growth distribution, and inflation: a centennial synthesis, Cambridge foumal of Economics, vol. 8, no. 2, 115-144

Nell, E. 1985. Jean Baptiste Marglin: a comment on 'Growth, distribution and inflation', Cambridge Goumal of Economics, vol. 9, no. 2, 173-178

Nell, E. J. 1992. Transformational Growth and Effective Demand: Economics afier the Capital Critique, London, Macmillan

Nichols, L. M. and Norton, B. 1991. Overhesd workers and political economy growth models, Review of Radical Palirical Economy, vol. 23, no. 1-2, 47-54

Pasinetri, L. L. 1962. Rate of profit and income distribution in relation to the rate of economic growth, Reviow of Economic Studies, vol. 29, no. 4, 267-279

Pivetti, M. 1988. On the monetary explanation of distribution: a rejoinder to Nell and Wray, Political Economy, vol. 4, no. 2, 275-283

Reynolds, P. J. 1987. A Synthesis of Kaleckian and Post Keynesian Economics, Brighton, Wheatsheaf

Robinson, J. 1962. Essays in the Theory of Economic Growth, London, Macmillan

Roncaglia, A. 1990. Is the notion of long-period positions compatible with the classical political economy, Political Economy, vol. 6, no. 1-2, 103-111

Rowthom, B. 1981. Demand, real wages and economic growth, Thames Papers in Political Economy, Autumn, 1-39. Reprinted in Studi Economici, vol. 18, 1982, (3-54), and also in M. C. Sawyer (ed.), Post-Keymesian Economics, Aldershot, Edward Elgar

Sarantis, N. 1990-91. Distribution and terms of trade dynamics, inflation, and growth, foumal of Post Keynesian Economics, vol. 13, no. 2, 175-198

Sarkar, P. 1993. Distribution and growth: a critical note on 'stagnationism', Review of Radical Patitical Economy, vol. 25, no. 1, March, 62-70

Sawyer, M. 1994. Prices, capacity utilisation and employment in the post-Keynesian traditions, in Dut, A. K. (ed.), New Directions in Analytical Pblitical Economy, Aldershot, Edward Elgar

Scherer, F. M. 1970. Industrial Market Structure and Economic Pefformance, Chicago, Rand McNally

Shipley, D. D. 1981. Pricing objectives in British manufacturing industry, Journal of Industrial Economics, vol. 29, no. 4, 429-443

Skott, P. 1989. Conflict and Effective Demand in Economic Growth, Cambridge, Cambridge University Press

Spaventa, L 1970. Rate of profit, rate of growth, and capital intensity in a simple production model, Oxford Economic Papers, vol. 22, no. 2, 129-147

Steedman, I. 1992. Questions for Kaleckians, Revire of Patitical Economy, vol. 4, no. 2, 125-151

Steindl, J. 1952. Marurity and Stagnation in American Capitalism, Oxford, Basil Blackwell

Steindl, J. 1979. Stagnation theory and stagnation policy, Cambridge foumal of Economics, vol. 3, no. $1,1-14$

Taylor, L. 1991. Income Distribution Inflation, and Growth: Lectures on Structuralist Macroeconomic Theory, Cambridge MA, MTT Press

Vianello, F. 1985. The pace of accumulation, Political Economy, vol. 1, no. 1, 69-87 


\section{M. Lavoie}

Vianello, F. 1989. Effective demand and the rate of profit: some thoughts on Marx, Kaleckl and Sraffa, in Sebastiani, M. (ed.), Kalecki's Relevance Today, New York, St. Martin's Press

Weisskopf, T. E. 1979. Marxian crisis theory and the rate of profit in the postwar US economy, Cambridge Youmal of Economics, vol. 3, no. 4, 341-379

Wood, A. 1975. A Theory of Profits, Cambridge, Cambridge University Press

You, J. 1994. Macroeconomic structure, endogenous technical change and growth, Cambridge Foumal of Economics, vol. 18, no. 2, 213-233 